\title{
Transfer out Patients Receiving Antiretroviral Therapy from Programme Clinic: A Potential "Leak" in the HIV Treatment Cascade
}

\author{
Manisha Ghate ${ }^{1}$, Sunil Zirpe ${ }^{1}$, Nilam Gurav ${ }^{1}$, Ramesh Paranjape ${ }^{1}$, Bharat Rewari², \\ Raman Gangakhedkar ${ }^{1}$ \\ ${ }^{1}$ National AIDS Research Institute, Pune, India \\ ${ }^{2}$ National AIDS Control Organization, New Delhi, India \\ Email: mghate@nariindia.org
}

Received 8 September 2014; revised 5 October 2014; accepted 1 November 2014

Copyright (C) 2014 by authors and Scientific Research Publishing Inc.

This work is licensed under the Creative Commons Attribution International License (CC BY). http://creativecommons.org/licenses/by/4.0/

(c) $\underset{\mathrm{EY}}{0}$ Open Access

\section{Abstract}

Background: India has scaled up ART programme very rapidly. Though there are reports on retention of patients in the national programme, data on transfer out patients within the ART centers are scanty in India. Methods: This is a retrospective study of patients receiving antiretroviral treatment between January 2006 and July 2013. The patients who were transferred out from the ART center at National AIDS Research Institute in Pune were included in the study. The data on whether they reached the respective ART centers were collected either by making telephonic calls to the patients and/or to the respective ART centers. Results: Of the total 3015 patients ever started on treatment from the ART center, $158(5.24 \%)$ were transferred out to other ART centers. Of these, $123(77.8 \%)$ patients reached other centres and they were "transferred in". However, 15 (9.5\%) did not reach to respective ART centers and information could not be obtained for 20 $(12.7 \%)$ transferred out patients. The analysis showed that those who were not living with their partners were 4.53 times more likely to not to reach the preferred ART centre after taking transfer [OR, 95\% CI: $(1.24-16.51), p=0.022]$. Conclusion: Our data suggest that significant number of transfer out patients is lost in HIV treatment cascade. Considering the total PLHIV on treatment in the country, this group adds significantly to the burden of lost to follow up patients. It is important to strengthen the system of tracking the transfer out patients in the programme which will help in patching an important leak in the cascade of HIV care. 


\section{Keywords}

\section{HIV, AIDS, Transfer out, ART Centre}

\section{Introduction}

India has scaled up its ART programme rapidly. As on April 2013, a total of 407 ART Centres are functional in 31 States and Union Territories and more than 0.65 million patients were receiving antiretroviral treatment (ART) at these centres [1]. Retention in HIV care is important for optimal treatment outcomes and effective positive prevention especially in view of published reports on loss to follow ups. The category of "transfer out" is used to indicate patients who actively seek a transfer to another government programme facility for their convenience. There are many reports from the developing countries on the status of patients that are transferred from one government facility to other [2] [3]. Though it is expected from each ART centre facility to keep the record of whether all "transfer out" patients are "transferred in"; the published data on whether the transferred out patients really reach another health care facility in India are scanty. This is important from the patients' as well as public health view point as there is a possibility that transfer out may not reach the ART centre, become loss to follow up and develop drug resistance. In this paper, we reported whether the patients that were "transfer out” on antiretroviral therapy from ART centre at National AIDS Research Institute (NARI) in Pune reached to respective ART centres for treatment continuation.

\section{Materials and Methods}

The National AIDS Control Organization (NACO) extended free ART roll out programme in December 2005 to NARI, Pune to provide care and support to HIV infected patients that were eligible to receive free ART as per the National guidelines [4]. In this retrospective study, all patients that were receiving antiretroviral treatment (on ART) between January 2006 and July 2013 were included.

When the eligible patients were started on ART, their demographic, biological and clinical details were entered into the white cards provided by the programme. They received drugs for one month and were requested to come back for follow up and to collect drugs for the next one month. The data for all visits was entered in the cards and green booklets with all the treatment details provided to patients. If any patient wished a transfer to another ART centre facility under the national programme for their convenience of taking treatment, the name of the new facility to which the patient wanted transfer was documented in the ART register and the treatment status was changed to "transfer-out". The patients were given his/her ART programme card, a transfer out letter and a month's supply of drugs to take to the new facility as per the operational guidelines [5]. At the new facility, the patient was "transferred in" with a new ART number related to that facility. The previous data was available to the ART centre from the programme card sent with the patient.

\section{Data Collection and Statistical Analysis}

The approval from the National AIDS Control Organisation for use of routine programmatic data for monitoring and evaluation was obtained. The ethics committee approval was obtained for the data analysis. The registers of all patients taking ART between January 2006 and July 2013 were reviewed, and data of those who were transferred out to another facility was considered for analysis. The telephonic calls were made by the counselors either to the patients and/or to the ART centre to verify whether the patients had reached the new ART centre and had continued their treatment.

Binary logistic regression was used to find the predictors of the patients who did not reach the new ART centre. As the number of patients who did not reach the new ART centre was small, age and gender controlled patients that reached the new facility were considered in 1:3 proportions for the appropriate comparison.

The data of patients who reached and could not reach the new ART centre after transfer out was entered in the software. The data was analyzed by SPSS (16.0 version). 


\section{Results}

Total 3015 patients were ever started on ART in the programme clinic till July 2013 at National AIDS Research Institute. Of these 158 (5.24\%) patients on treatment were transferred out to another ART centre on their request and were considered for analysis.

Of the 158 patients receiving antiretroviral therapy, 123 (77.8\%) patients reached to the new ART centres and were continued on the treatment; 15 (9.5\%) did not reach to respective ART centre and the information could not be obtained for 20 (12.7\%) patients. The baseline demographic and biological characteristics of all the patients are shown in Table 1.

The binary logistic regression analysis of patients who reached vs. those who could not reach the new programme clinic showed that the possibility of not reaching the new clinic was 4.5 [OR, 95\% CI: (1.24 - 16.51), p $=0.022$ ] times more for patients who were not living with partner (single, divorced, widowed) (Table 2).

\section{Discussion}

As the national programme is scaling up, there is a concern about retention of patients on therapy. There are reports from ART centres in India on outcomes of patients taking antiretroviral therapy that include prevalence and reasons for loss to follow up [6] [7]. However, the data on "transfer out" patients is scanty. Our study has reported whether the transfer out patients reach the new facility under the programme for treatment continuation. This is important for the retention of patients in the programme.

Overall transfer out number from our centre was less as compared to reports from Africa [2] [3]. The proportion of patients that reached the new clinic was same with respect to age, gender, employment, education and baseline CD4 counts.

The analysis showed that the patients that were single, divorced or widowed were significantly less likely to reach the new facility as compared to others. This finding suggests that the support of partner or care giver is important in identifying the new centre at different place in addition to taking care of other aspects of daily living. The patients should be encouraged to provide the new residential address after taking the transfer so that help from outreach workers from the new facility can be taken for contacting the patient.

The real time linkage with the State AIDS Control Societies and the ART centres at national level to which

Table 1. Baseline characteristics of patients that were transferred out on treatment from NARI ARTC to another programme clinic.

\begin{tabular}{|c|c|c|c|c|}
\hline \multicolumn{2}{|c|}{ Characteristics } & \multirow{2}{*}{$\begin{array}{c}\text { Transfer out patients } \\
\text { that reached new } \\
\text { clinic }(n=123) \\
66(53.7)\end{array}$} & \multirow{2}{*}{$\begin{array}{l}\text { Transfer out patients } \\
\text { that did not reach } \\
\text { new clinic }(\mathrm{n}=15) \\
7(46.7)\end{array}$} & \multirow{2}{*}{$\begin{array}{c}\text { Transfer out patients } \\
\text { who could not be } \\
\text { contacted }(n=20) \\
9(45.0)\end{array}$} \\
\hline & Male & & & \\
\hline ender & Female & 57 (46.3) & $8(53.3)$ & $11(55.0)$ \\
\hline \multirow{2}{*}{ Age } & $<40$ & $86(69.9)$ & $10(66.7)$ & $12(60.0)$ \\
\hline & $\geq 40$ & $37(30.1)$ & $5(33.3)$ & $8(40.0)$ \\
\hline \multirow{2}{*}{ Employment } & Employed & $80(65.0)$ & $10(66.7)$ & $15(75.0)$ \\
\hline & Unemployed & $43(35.0)$ & $5(33.3)$ & $5(25.0)$ \\
\hline \multirow{2}{*}{ Marital status } & Living with partner & $79(64.2)$ & $4(26.7)$ & $10(50.0)$ \\
\hline & Not living with partner & $44(35.8)$ & $11(73.3)$ & $10(50.0)$ \\
\hline \multirow{2}{*}{ Education } & Up to secondary & $47(38.2)$ & $8(53.3)$ & $11(55.0)$ \\
\hline & Secondary \& above & 76 (61.8) & $7(46.7)$ & $9(45.0)$ \\
\hline \multirow{2}{*}{$\begin{array}{l}\text { Baseline CD4 count } \\
\text { (cells } / \mathrm{mm}^{3} \text { ) }\end{array}$} & $\leq 200$ & $69(57.0)$ & $11(78.6)$ & $13(65.0)$ \\
\hline & $>200$ & $52(43.0)$ & $3(21.4)$ & $7(35.0)$ \\
\hline
\end{tabular}


Table 2. Associated baseline demographic and biological characteristics of transferred out patients that did not reach vs. reached new clinic.

\begin{tabular}{|c|c|c|}
\hline \multirow{2}{*}{ Characteristic } & \multicolumn{2}{|c|}{ Univariate analysis } \\
\hline & OR $(95 \%, \mathrm{CI})$ & P-value \\
\hline \multicolumn{3}{|l|}{ Education $(n=60)$} \\
\hline Up to secondary & $1.88(0.58-6.13)$ & \multirow{2}{*}{0.293} \\
\hline Secondary \& above & 1 & \\
\hline \multicolumn{3}{|l|}{ Employment $(n=60)$} \\
\hline Yes & $1.00(0.29-3.45)$ & \multirow[b]{2}{*}{1.000 (NS) } \\
\hline No & 1 & \\
\hline \multicolumn{3}{|l|}{ Marital status $(n=60)$} \\
\hline Living with partner & 1 & \multirow{2}{*}{0.022} \\
\hline Not Living with partner & $4.53(1.24-16.51)$ & \\
\hline \multicolumn{3}{|l|}{ Baseline CD4 $(\mathrm{n}=57)^{*}$} \\
\hline$\leq 200$ cells $/ \mathrm{mm}^{3}$ & $1.77(0.43-7.38)$ & \multirow{2}{*}{0.433} \\
\hline$>200$ cells $/ \mathrm{mm}^{3}$ & 1 & \\
\hline \multicolumn{3}{|c|}{ Duration of follow up in the centre $(n=60)$} \\
\hline$<2$ years & $1.10(0.32-3.79)$ & \multirow{2}{*}{0.876} \\
\hline$\geq 2$ years & 1 & \\
\hline \multicolumn{3}{|l|}{ Location of new clinic $(n=60)$} \\
\hline Within State (Maharashtra) & $0.65(0.06-7.74)$ & \multirow{2}{*}{0.734} \\
\hline Out of State & 1 & \\
\hline
\end{tabular}

Note: *Baseline CD4 count was not available for 3 patients.

the patients are transferred out may help. The operational procedures outlined in the guidelines [5] for confirmation of "transfer in" should be strengthened which will subsequently help in tracking the patients in timely manner.

The study has some limitations. Our transfer out number was small. Though there was no statistical significance, transfers out of state were more likely to be challenging. It is possible that these patients went back to states where social stigma is reported to be high and faced issues in accessing care. The data for all patients that were "transferred in" could not be verified from the respective ART centres due to problems like telephonic connectivity issues and tracing correct name of the patient. The information on some patients could not be obtained as the exact details of centre where the patients were transferred out were not documented. It was difficult to obtain their information from the new ART centres.

To the best of our knowledge, this is the first report on transfer out patients from India. Our data suggests that significant number of transfer out patients is lost in HIV treatment cascade. Considering the total PLHIV on treatment in the country, this group adds significantly to the burden of lost to follow up patients.

\section{Conclusion}

It is important to strengthen the system of tracking the transfer out patients in the programme which will help in patching an important leak in the cascade of HIV care. 


\section{References}

[1] http://webcache.googleusercontent.com/search?q=cache:http://pag.ias2013.org/PAGMaterial/PPT/262_191/final.pptx

[2] Nglazi, M.D., Kaplan, R., Orrell, C., Myer, L., Wood, R., et al. (2013) Increasing Transfers-Out from an Antiretroviral Treatment Service in South Africa: Patient Characteristics and Rates of Virological Non-Suppression. PLoS ONE, 8, e57907. http://dx.doi.org/10.1371/journal.pone.0057907

[3] Kwong-Leung Yu, J., Tok, T.-S., Tsai, J.-J., Chang, W.-S., Dzimadzi, R.K., et al. (2008) What Happens to Patients on Antiretroviral Therapy Who Transfer out to Another Facility? PLoS ONE, 3, e2065. http://dx.doi.org/10.1371/journal.pone.0002065

[4] http://naco.gov.in/upload/Policies\%20\&\%20Guidelines/1.\%20Antiretroviral\%20Therapy\%20Guidelines\%20for\%20HI V-Infected\%20Adults\%20and\%20Adolescents\%20\%20Including\%20Post-exposure.pdf

[5] (2012) Operational Guidelines for ART Services. http://www.naco.gov.in/upload/Publication/Treatment\%20Care\%20and\%20support/Operational\%20guidelines\%20for \%20ART\%20services.pdf

[6] Sharma, S.K., Dhooria, S., Prasad, K.T., George, N., Ranjan, S., Gupta, D., Sreenivas, V., Kadhiravan, T., Miglani, S., Sinha, S., Wig, N., Biswas, A. and Vajpayee, M. (2010) Outcomes of Antiretroviral Therapy in a Northern Indian Urban Clinic. Bulletin of the World Health Organization, 88, 222-226. http://dx.doi.org/10.2471/BLT.09.068759

[7] Bachani, D., Garg, R., Rewari, B.B., Hegg, L., Rajasekaran, S., Deshpande, A., et al. (2010) Two-Year Treatment Outcomes of Patients Enrolled in India's National First-Line Antiretroviral Therapyprogramme. The National Medical Journal of India, 23, 7-12. 
Scientific Research Publishing (SCIRP) is one of the largest Open Access journal publishers. It is currently publishing more than 200 open access, online, peer-reviewed journals covering a wide range of academic disciplines. SCIRP serves the worldwide academic communities and contributes to the progress and application of science with its publication.

Other selected journals from SCIRP are listed as below. Submit your manuscript to us via either submit@scirp.org or Online Submission Portal.
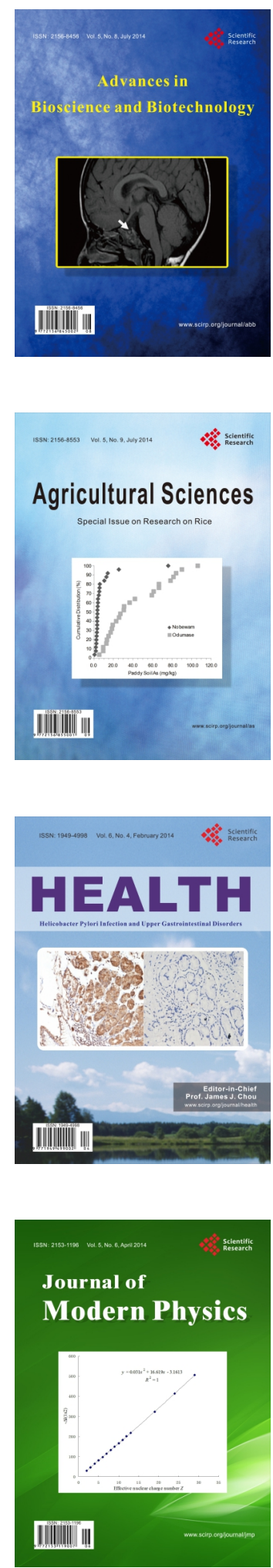
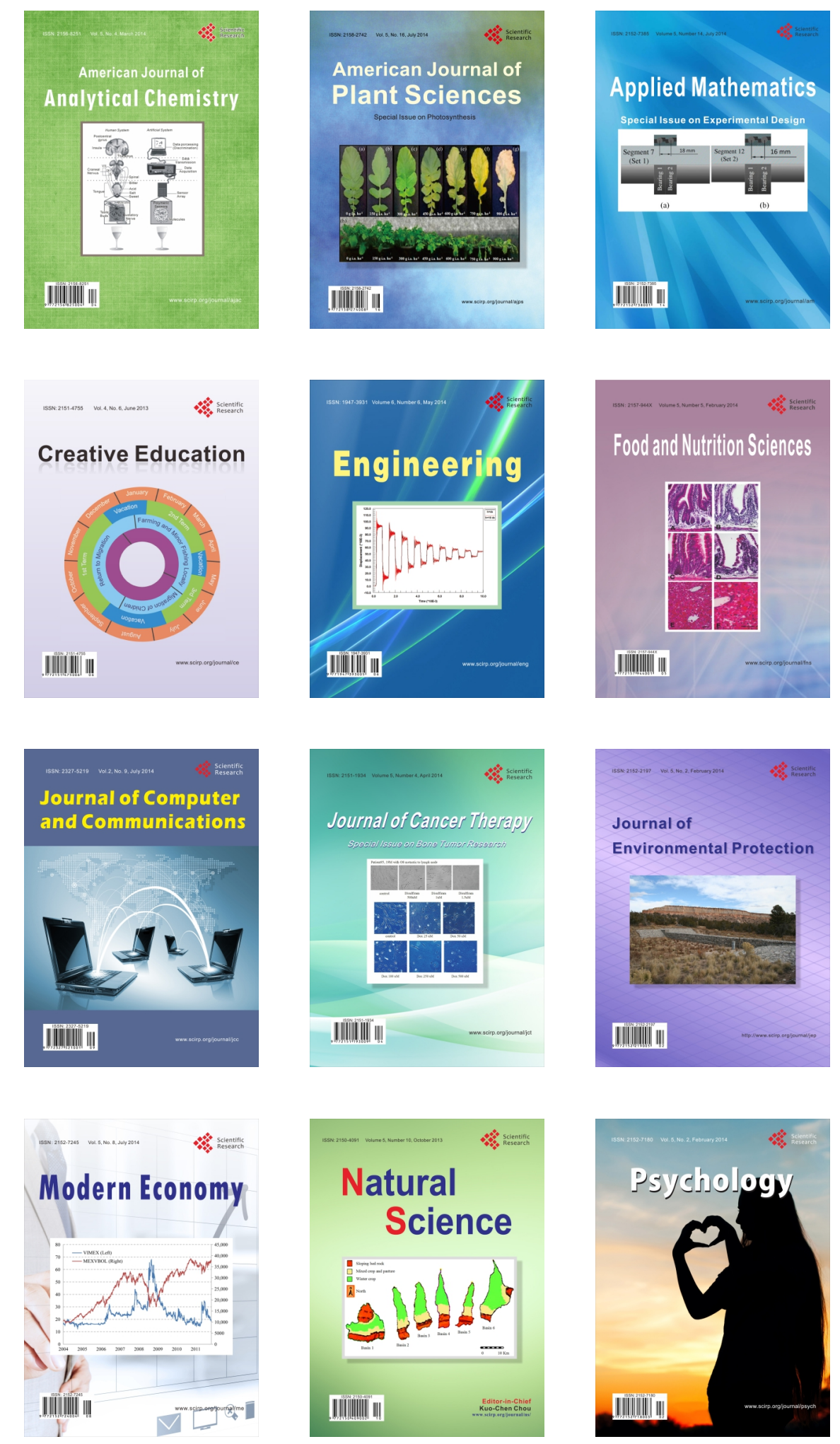